Arab World English Journal (AWEJ) Volume 12. Number3 September 2021

DOI: https://dx.doi.org/10.24093/awej/vol12no3.24

Pp.351-365

\title{
Gifted High School Students' Needs for English Learning in Vietnam Contexts
}

\author{
Do Minh Hung \\ Foreign Languages Faculty, Dong Thap University \\ Cao Lanh City, Vietnam \\ Corresponding Author: dmhung@dthu.edu.vn
}

Nguyen Thi Thu Ai

Ca Van Thinh High School

Ben Tre City, Vietnam

Received: 5/21/2021

Accepted: 9/3/2021

Published: 9/24/2021

\section{Abstract}

The learning needs of English students have been researched over the past decades in different countries, especially among non-speaking English ones. The core goal of these studies was to examine if learner needs/wants and learning outcomes of the English course/curriculum provided are sufficiently matched, i.e., whether or not students feel satisfied (because their needs/wants are met). Expanding this line of research, the current study attempts to find out the needs for English learning among gifted high school students in the current Vietnam context by seeking the answer to the main question: How do these students report their needs for English learning? The findings are supposed to provide useful insights into this English learning teaching setting. One hundred and eighty English-majored students from five gifted high schools in five provinces of Vietnam participated in a questionnaire-interview survey. The obtained results show that most participants opted for English because they needed it for future employment and cross-cultural/national communications for long-term purposes. As a result, they wanted to practice more English speaking and listening skills rather than other components of English knowledge (pronunciation, grammar, vocabulary) and skills (reading, writing). Yet, their English practices in the classroom did not place much emphasis on speaking-listening skills, i.e., their needs were not very satisfactorily met. Some of the findings echo those of previous research, and some are first reported in the current study.

Keywords: English learning, gifted high school, needs analysis, practice, survey, Vietnam context

Cite as: Do, M. H., \& Nguyen, T. T. A. (2021). Gifted High School Students' Needs for English Learning in Vietnam Contexts. Arab World English Journal, 12 (3) 351-365.

DOI: https://dx.doi.org/10.24093/awej/vol12no3.24 


\section{Introduction}

In addition to regular high schools throughout the country, there is a gifted high school system in Vietnam (MOET, 2014). Gifted high schools or specialized high schools in Vietnam are designated as State-schools for students with gifted potentials, who excel in a specific subject of foreign languages (English, French or Japanese), Maths, natural sciences (Physics, Chemistry or Biology), or social sciences (Literature or History). Currently, each province or major city in Vietnam has one or two gifted high schools. The enrollments for gifted high schools are held yearly. For English majors, candidates have to take written exams in English (as a foreign language, or EFL), Maths, and Literature. Thus, English-majored students from this school type are deemed to have more explicit English learning potentials, needs, and expectations than those learning EFL in regular high schools, and thereby EFL teachers have to design and offer intensive English practices which involve a total of four or five periods a week (one period is 45 minutes) per class. They also have to design extra courses for their classes since currently there is no national specialized syllabus or textbooks for English-majored students in gifted high schools in Vietnam (Cao, Ta, \& Hoang, 2016). Therefore, students' learning needs should be taken into sufficient considerations by EFL teachers working in these schools because student engagement will be promoted when course plans and English lessons are adequately tailored to students' interests, needs, and current level of English proficiency (Chatzikyriakou \& Zafiri, 2019; Long, 2005). Otherwise, their motivations in learning are gradually diminished.

Research on needs analysis of English learners has been done over the past decades, such as Akbari (2016), Dissanayake and Harun (2012), Ho (2017), Loan and Dan (2018), Nguyen (2011), and Zafar (2020). Results from previous studies in needs analysis of English learners (as seen in the next section) have not been rigorous or conclusive. Furthermore, although the gifted high school system has been in operation for several years, no research on EFL students' learning needs from gifted schools in Vietnam has been conducted. Thus, little is known about students specializing in English from this high school system. On these rationales, the current study has been designed. It aims to gain insightful information on the English learning needs of students from gifted high schools located in different provinces of the Mekong Delta region (South-West of Vietnam). Specifically, it seeks answers to two major questions, namely (1) How do gifted high school students describe their needs for English learning? (2) How much do they feel satisfied with the English practices provided?

Findings from this current study are helpful. Firstly, it provides current evidence of involved students' English learning needs, and the degree of their needs met concerning English practices provided by teachers in the classroom. With students from different provinces, obtained results could apply to the evaluation of English teaching-learning in gifted schools in the Mekong Delta region. Secondly, the results are supposed to benefit English teachers working in gifted high schools as well as stakeholders (as the intended audience) with blueprints for English course plans and lesson activities to meet students' needs for English learning better. Thirdly, this study could be used as a premise for further studies in the settings of gifted and other high schools in Vietnam, and beyond in the field of learning needs analysis.

\section{Literature Review}

\section{Definition of Needs Analysis}

Since the term first appeared in the 1920s, needs analysis is a technical term related to language teaching (White, 1988). However, it was not until the 1970s and early 1980s that needs 
analysis was recognized as an essential component of syllabus design. Nunan (1988) defined needs analysis as techniques and steps for gathering information to be applied in syllabus design. In the same line, Brown (1995) delineated needs analysis as "the systematic collection and analysis of all relevant information necessary in the language learning requirements of the students within the context of the particular institutions involved in the learning situation" (p.12). The relevant information about language learners in a particular context includes their desires, demands, expectations, lacks, requirements, and constraints (Brindley, 1989). Meanwhile, Hutchinson and Waters (1987) viewed that learners' motivation, learning strategies and skills, background knowledge, and learning contexts should all be taken into consideration in needs analysis.

It is, therefore, needs analysis is first and foremost a collection of relevant information about target learners in particular contexts. From this perspective, the current study focussed on collecting target learners' needs for English learning in Vietnam contexts. This can translate into two significant subcategories (Hutchinson \& Waters, 1987): the first is "Necessities," which is determined by the demands of English uses in the target situations perceived by the learners; the second subcategory is "Wants," which indicates how the learners consciously want to learn English to get prepared for and function effectively in the prospective target situations. In this framework, the related questions for information collected may include Why is the target language needed? How will the language be used? What will the content areas be? Who will the learners use the language with? Where and when will the language be used? (Hutchinson \& Waters, 1987; Zafar, 2020).

\section{Benefits of Needs Analysis}

Needs analysis yields useful pedagogical implications because "the purpose of the needs analysis is to identify the target language teaching/learning needs in order to design an effective curriculum" (Sönmez, 2019, p.8). It is deemed to help teachers have a basis for organizing inclass activities in which students can use their existing skills and language knowledge to meet the requirements of their real-life situations in meaningful ways (Nunan, 1988). Meanwhile, Read (2008) highlighted that needs analysis should be a core component of assessments that test students' performance on tasks related to real-life situations and Nguyen et al. (2021) underline, "In reality, needs analysis/needs assessment has been substantially concerned in education and language education particularly" (p.113). It plays an integral role in language curriculum planning and development because a program will be more appealing and successful if it aims to meet learners' perceived needs (Dooey, 2010) and student voices can inform teachers of their objectives that would have remained unnoticed or the gap between what is currently being taught and what needs to be taught for students' future careers (Poedjiastutie \& Oliver, 2017), which is also what the current study aims at.

\section{Previous Studies}

Previous studies relating to needs analysis were conducted to collect relevant information about learners on two major subcategories of Necessities and Wants. Instruments often used to collect data are "questionnaire, interview, observation, discussion, telephone interview, and their combinations" (Sönmez, 2019, p.10) among learners of EAP (English for Academic Purposes), EGP (English for General Purposes), and ESP (English for Specific Purposes). The following are typical ones. 
Kazar and Mede (2015) examined the target needs of 84 students in an ESP program at a private university in Turkey. The findings via a questionnaire-interview survey revealed that the ESP program should focus on the effective use of language strategies (speaking, listening, reading, and writing) in students' workplace, academic setting, and the outside world. In other words, participants did not find the program fully meet their target needs. Similar findings are reported in studies by Akbari (2016) in Iran, Dissanayake and Harun (2012) in Sri Lanka, Gass (2012) in Thailand, Gborsong et al. (2015) in Ghana, Ibrahim (2016) in Sudan, Nurakhia and Palupi (2018) in Indonesia, and Priya (2014) in India.

Recently, Chatzikyriakou and Zafiri's study (2019) exclusively surveyed 54 EFL teachers in the Greek private sector and reported that participants acknowledged the importance of needs analysis and highlighted its usefulness in the course and syllabus design. They were aware of students' needs in various ways, such as through observation, formal testing, evaluation of tasks and activities, etc.; thereby, they utilized the results of their needs analysis in the course and syllabus design, mainly by adapting instructional material to suit their students' needs and to select the appropriate tasks and activities daily for them. Also, a recent questionnaire survey research by Lou, Li, and Zhao (2020) in China among 110 first-year ESP students reported that writing and speaking should be emphasized although participants ranked reading and listening as the first importance. Yet, drawing from the interviews among vocational college graduates in Oman, Al Hilali and McKinley (2021) suggested that ESP course designers need to address the text-context relationship and contextualised nature of written genres.

In Vietnam, Nguyen (2011) conducted a study on learners' academic and occupational needs at a Vocational College in the Mekong Delta (South of Vietnam) involving 150 secondyear students and eight ESP teachers. Both teachers and students were asked to complete the questionnaires. The results showed that students wanted their courses to focus more on improving reading and listening skills than writing and speaking, but teachers placed less emphasis on listening skills than the other three skills. Also in Ho's study (2017), the questionnaire survey among 92 students and eight ESP teachers from a college in Vietnam reported that speaking and reading skills should be prioritized, work-place oriented skills such as telephoning, writing emails, reading business texts, and interviewing should be included; content-based and skill-integrated materials should be used; interactive and project-based activities should be deployed. Meanwhile, 148 EGP college students and four EFL teachers were involved in a survey interview study by Loan and Dan (2018). Findings revealed that students were most interested in knowledge and language input. They also preferred extra-curricular activities, watching videos, or small group discussions in the language learning process, but in general terms, their learning needs were different from the actual course they received.

As can be seen above, previous research results vary from one context to another, but one shared point across the board is that most participants' learning needs under investigation did not gain much satisfaction, mostly because either course goals or teacher instructions were not aligned with learner needs. All previous studies were conducted in university and private language center contexts, i.e., students and teachers from high schools were not included in the analyses. Furthermore, no previous research provided sufficient statistical evidence by matching what learners' learning needs/wants are and what they are offered in English practices provided in the classroom to identify learners' level of satisfaction or wants to be met. Thus, against this background, the current study has been designed to address a gap in the literature regarding 
learning needs analysis of English-majored students from gifted high schools in the Mekong Delta, Vietnam.

\section{Methods}

As defined above, needs analysis is a collection of relevant information about target learners in particular contexts, i.e., relying as much as possible on the learners' views of the situation being studied (Creswell, 2014). Accordingly, the current study was designed as survey research (Bhattacherjee, 2012) with data collected through questionnaires and interviews because questionnaires can supply quantitative data of a large number of respondents while qualitative interview data usually contain a clear, deep understanding of informants' perceptions and practices (Kendall, 2008). As Sönmez (2019) suggests, "the needs of language education should be examined both qualitatively and quantitatively. For this reason, qualitative and quantitative data collection tools should be used together to determine needs" (p.12). Thus, in the current study, the combination of two methods was employed to validate data and provide more detailed information about participants' needs for English learning and their satisfaction in the current Vietnam context because the advantages of collecting both quantitative data and qualitative data prove advantageous to best understand a research problem (Creswell, 2014).

\section{Participants}

Participants in the current study were 180 English-majored students of $12^{\text {th }}$-grade, randomly selected from five gifted high schools in five out of thirteen provinces in the Mekong Delta region (with approximately one-fifth of current Vietnam's total population). They were between 18 and 20 years of age at the research time (the academic year 2019 - 2020). The participants all speak Vietnamese as their mother tongue and English as a Foreign Language (EFL) at approximately a lower-intermediate level. They come from different parts of their home provinces in the Mekong Delta and were admitted to gifted high schools after passing the entrance exams in three core subject papers: English, Maths, and Literature.

\section{Participants for Questionnaire}

Participants in the current study were 126 females (70\%) and 54 males (30\%). At the time of research, they were twelfth-grade students coming from five gifted high schools, but the real names of these schools were changed into school 1, school 2, school 3, school 4, and school 5 in this study. The twelfth-grade students were chosen to participate in the study because they had already experienced the whole learning curriculum designed for English-majored students. Among 180 participants, 29 were from school 1 (16.1\%), 35 from school 2 (19.5\%), 33 from school 3 (18.3\%), 21 from school 4 (11.7\%), and 62 from school 5 (34.4\%). As a result, the number of participants was unevenly distributed in each school for two main reasons. First, two out of the five schools ran two English-majored classes while the others had only one class. Second, the questionnaire designed in Google Form was sent to the target schools when the pandemic Covid-19 widely broke out in Vietnam, so all gifted high schools in the Mekong Delta were closed, and many students declined to take part in the survey. 
Arab World English Journal (AWEJ) Volume 12. Number 3. September 2021

Gifted High School Students' Needs for English Learning in Vietnam

Do \& Nguyen

Participants for Interview

After participating in the questionnaire, ten participants were interviewed (one boy and one girl in each school). The interviewees' information is displayed in Table one.

Table 1. Descriptions of participants for interview

\begin{tabular}{cccc}
\hline $\begin{array}{c}\text { Interviewed Student } \\
\text { (St.) }\end{array}$ & Gender & Age & School \\
\hline St. A & Male & 18 & School 1 \\
\hline St. B & Female & 18 & School 2 \\
\hline St. C & Male & 18 & \\
\hline St. D & Female & 18 & School 3 \\
\hline St. E & Male & 18 & School 4 \\
\hline St. F & Female & 18 & \\
\hline St. G & Male & 18 & School 5 \\
\hline St. H & Female & 18 & \\
\hline St. I & Male & 18 & 18 \\
\hline St. J & Female & &
\end{tabular}

\section{Research Instruments}

The questionnaire survey in this study was adapted from previous research by Hutchinson and Waters (1987), Loan and Dan (2018), and Seedhouse (1995). It was shaped by a 5-pointLikert scale with three main sections. Section A asked participants about personal information such as age, gender, and school name. Section B focused on their needs of English learning, allowing participants to express: (a) how much they agree or disagree with each item moving from most negative to most positive (strongly disagree $=1$, disagree $=2$, neutral $=3$, agree $=4$, and strongly agree =5); (b) how much practice they want to get in each item (not at all=1, slightly=2, moderately $=3$, considerably $=4$, and a great deal of=5). Section C explored participants' evaluation on in-class practices of English learning and was shaped in the format of " $n o t$ at all $=1$, slightly $=2$, moderately $=3$, considerately $=4$, a great deal $=5$ '.

Table 2. Summary of the questionnaire

\begin{tabular}{|c|c|c|}
\hline Section & Clusters & Questions \\
\hline \multirow[t]{3}{*}{ A. Personal information } & Age & 1 \\
\hline & Gender & 2 \\
\hline & School names & 3 \\
\hline \multirow{2}{*}{$\begin{array}{l}\text { B. Students' needs of } \\
\text { English learning }\end{array}$} & Necessities for learning English & 4 (10 items) \\
\hline & Wants in English knowledge \& skills & 5 (7 items) \\
\hline C. Students' evaluation & In-class practices provided & 6 (7 items) \\
\hline
\end{tabular}

To address the reliability and validity of the questionnaire, the researchers (the authors of this paper) first invited three knowledgeable and experienced EFL experts to give their feedback on the questionnaire. The feedback was on its contents, format, word choices, and grammatical structures. Then, the researchers enhanced the quality of the questionnaire based on the three experts' comments and suggestions. Next, it was translated into Vietnamese to avoid misunderstanding and ambiguity since all respondents are non-English native speakers. Then, the researchers had three EFL teacher colleagues double-check the two versions for comparison and adjustment before coming to the final ones equivalent in meaning.

\section{Semi-structured Interview}

The interview questions were designed based on the results of the questionnaire to get more insightful information and clear explanations for participants' numerical responses. After 
Arab World English Journal (AWEJ) Volume 12. Number 3. September 2021

Gifted High School Students' Needs for English Learning in Vietnam

Do \& Nguyen

the completed questionnaire copies were sent back and analyzed by the Statistical Package for Social Sciences (SPSS) version 20.0, the interviews were designed, piloted, and conducted.

\section{Data Collection Procedures \\ Questionnaire}

Before the study was officially conducted, the Vietnamese version of the questionnaire designed on Google Form was first delivered to an English-majored class of a gifted high school in the Mekong Delta. There were 35 twelfth-grade English-majored students in this class, but only 26 sent back the pilot questionnaire. Data from the pilot questionnaire were double-checked and analyzed by SPSS. The reliability score of the questionnaire (24 items) was $\alpha=.830(>0.7$, the required coefficient). Next, the official questionnaire was delivered to seven English-majored classes in five gifted high schools. After two weeks, 180 completed questionnaire copies were sent back. At this time, the researchers ran statistical tests on SPSS to gain the results.

\section{Semi-structured Interviews}

Two students (one boy and one girl) taking part in piloting the questionnaire were interviewed to test the validity of the interview protocol. Two girls left their phone numbers in the pilot questionnaire, but the researchers randomly chose one and had the class teacher invite one boy. Then, the two selected students were asked the interview questions, and some follow-up questions arising during the interview. All their responses were recorded and listened to many times by the researchers. After that, the interview questions were adjusted based on pilot results and the comments from two EFL teacher colleagues. Accordingly, six main questions made up the final interview protocol (Appendix A).

Of the 180 students completing the questionnaire, twelve left their contact phone numbers for the interview. However, only two schools had sufficient interview conditions (i.e., one boy and one girl from each school). To deal with this problem, the researchers phoned some students to invite them to join the interview. In the end, ten students from five schools willingly and voluntarily partook. Each interview lasted between 20 and 25 minutes via phone in Vietnamese to ensure a complete understanding during the interview. All the responses were recorded with the interviewees' permission. After that, the researchers transcribed the responses and then sent them back to the interviewees on their emails. Next, the researchers waited for all their confirmations before doing relevant analyses.

Table 3. Data collection timeline

\begin{tabular}{|c|c|}
\hline Research activities & Timeline \\
\hline Designing questionnaire & Week 1, 2, 3, 4 \\
\hline Piloting questionnaire & Week 5,6 \\
\hline Delivering and collecting questionnaire & Week 7,8 \\
\hline Running questionnaire SPSS tests & Week 9 \\
\hline Designing, piloting interview questions & Week 10, 11 \\
\hline Running interviews & Week 12 \\
\hline Analyzing and synthesizing data & Week $13,14,15$ \\
\hline
\end{tabular}




\section{Data Analysis Procedures}

First, a scale test was run to check questionnaire reliability (via SPSS version 20.0), followed by descriptive statistics tests on the data (with mean scores level: Very high $=4.5-5$; High=3.6 - 4.4; Medium=2.5 - 3.5; Low=1.0 - 2.4). Then, Sample T-tests were used to compare mean scores. For all analyses, differences were considered significant if $p<.005$.

For the interview data, the researchers had to listen to the interviewees' recorded responses several times to have exactly written transcriptions. Then, the transcribed responses were carefully read and reread, highlighted, and grouped into four themes, namely (1) participants' necessities for learning English, (2) their wants in English learning, (3) their satisfaction concerning their wants in English learning, (4) their suggestions for bettering existing curricula.

\section{Findings}

The scale test was run to test the questionnaire reliability before analyses. The test coefficient result was $\alpha=.85$. Thus, the questionnaire is reliable and valid for data analyses.

The findings are organized into three sections (a) students' necessities for English learning, (b) their wants in English learning, and (c) students' satisfaction. These three sections will be presented below in both questionnaire and interview results.

\section{Questionnaire Results}

\section{(a) Students' necessities for English learning}

In Table four, item (10) topping the list with a very high mean score (M=4.61) indicates that the students need to learn English because they believed it helped them get a good job in the future. It is followed by a high-level need group of six items one, two, three, five, seven, and eight. The rest three, six, and nine falls into the medium-level need. Noticeably, the lowest mean score $=3.00$ of the item nine reflects a non-imposition on the students (in this study) by family members to learn English.

Table 4. Necessities for English learning $(N=180)$

\begin{tabular}{|c|c|c|c|c|}
\hline Items & Min. & Max. & Mean & SD \\
\hline (1) Getting high marks at school. & 1.00 & 5.00 & 3.71 & 1.1 \\
\hline (2) Passing college entrance exams. & 1.00 & 5.00 & 4.06 & 1.0 \\
\hline (3) Gaining prizes in English competitions. & 1.00 & 5.00 & 3.08 & 1.0 \\
\hline (4) Travelling to other countries. & 1.00 & 5.00 & 4.25 & 0.9 \\
\hline (5) Earning international certificates. & 1.00 & 5.00 & 4.22 & 0.8 \\
\hline (6) Studying abroad in the future. & 1.00 & 5.00 & 3.30 & 1.1 \\
\hline (7) Having a great interest in English. & 2.00 & 5.00 & 3.96 & 0.9 \\
\hline (8) Communicating with foreigners. & 1.00 & 5.00 & 4.23 & 0.8 \\
\hline (9) My parents wanted me to be good at English. & 1.00 & 5.00 & 3.00 & 1.2 \\
\hline $\begin{array}{l}\text { (10) I believe that learning English is vital to get a good job in } \\
\text { the future. }\end{array}$ & 1.00 & 5.00 & 4.61 & 0.8 \\
\hline
\end{tabular}


Arab World English Journal (AWEJ) Volume 12. Number 3. September 2021

Gifted High School Students' Needs for English Learning in Vietnam

Do \& Nguyen

(b) Students' wants in English knowledge and skills

As shown in Table five, the mean scores of seven items are between 3.5 and 4.2 (out of 5), implying that students wanted to practice on English knowledge and skills. Specifically, they firmly believed that they would need more training in Speaking $(\mathrm{M}=4.31)$, followed by Listening $(\mathrm{M}=4.25)$ in the classroom than in Vocabulary, Pronunciation, Reading, Writing, or Grammar.

Table 5. Students' wants in English knowledge and skills $(N=180)$

\begin{tabular}{lcccc}
\hline Items & Min. & Max. & Mean & SD \\
\hline Grammar & 1.00 & 5.00 & 3.53 & .84 \\
\hline Vocabulary & 2.00 & 5.00 & 4.19 & .76 \\
\hline Pronunciation & 2.00 & 5.00 & 4.16 & .81 \\
\hline Listening & 2.00 & 5.00 & 4.25 & .76 \\
\hline Speaking & 1.00 & 5.00 & 4.31 & .78 \\
\hline Reading & 1.00 & 5.00 & 3.85 & .85 \\
\hline Writing & 1.00 & 5.00 & 3.76 & .90 \\
\hline
\end{tabular}

(c) Students' satisfaction

First, the results of questionnaire six (asking about how students are satisfied with their English practices in the classroom) are reported below:

Table 6. Students' satisfaction with English practices $(N=180)$

\begin{tabular}{lcccc}
\hline Items & Min. & Max. & Mean & SD \\
\hline Grammar & 2 & 5 & 3.98 & .95 \\
\hline Vocabulary & 1 & 5 & 3.99 & .86 \\
\hline Pronunciation & 1 & 5 & 3.32 & .95 \\
\hline Listening & 1 & 5 & 3.06 & .86 \\
\hline Speaking & 1 & 5 & 3.04 & .99 \\
\hline Reading & 2 & 5 & 3.71 & .83 \\
\hline Writing & 1 & 5 & 2.96 & .84 \\
\hline
\end{tabular}

As found in Table six, all seven items gain mean scores under 4.0, with only three of them falling into a high-level >3.60 (Grammar, Vocabulary, and Reading), and the rest just at a medium one. To identify any significant difference between students' wants (Table five above) and their actual English practices in the classroom, Paired-Samples T-Tests were run.

Table 7. Matching students' wants and received practices $(N=180)$

\begin{tabular}{lccc}
\hline & $\begin{array}{c}\text { received practices } \\
\text { (Mean score) }\end{array}$ & $\begin{array}{c}\text { Wants } \\
\text { (Mean score) }\end{array}$ & $\mathrm{p}$ \\
\hline Grammar & 3.98 & 3.53 & .000 \\
\hline Vocabulary & 3.99 & 4.19 & .009 \\
\hline Pronunciation & 3.32 & 4.16 & .000 \\
\hline Listening & 3.06 & 4.25 & .000 \\
\hline Speaking & 3.04 & 4.31 & .000 \\
\hline Reading & 3.71 & 3.85 & .071 \\
\hline Writing & 2.96 & 3.76 & .000 \\
\hline
\end{tabular}

Table seven reveals that students spent less time practicing Vocabulary, Pronunciation, Listening, Speaking, Reading, and Writing than their wants while they were provided more Grammar than expected. Thus, no complete match is found across the board. However, the 
Arab World English Journal (AWEJ) Volume 12. Number 3. September 2021

Gifted High School Students' Needs for English Learning in Vietnam

Do \& Nguyen

mismatch is not significant in the cases of Vocabulary $(\mathrm{p}=.009>.005)$ and Reading $(\mathrm{p}=.071>.005)$.

\section{Interview Results}

(a) Students' necessities for English learning

Nine out of ten interviewees completely agreed with the necessity of "learning English to get a good job in the future." They explained,

When we know English, we will get more chances of being employed, having high job positions, or getting high-paid employment in several areas. (St. B, St. C)

Also, seven of them revealed that they needed English because they wanted to communicate with foreigners.

I would rather use English to communicate with people coming from different parts of the world. (St. H)

Meanwhile, half of them claimed that English was the most popular language in global integration.

English is an international language. As I know, English is now spoken in about 53 countries, and there are 400 million people around the world using it. (St. F)

Thus, it is clearly shown that participants in this study understood paramount target situations requiring them to learn English, i.e., they know well the necessities for their learning needs of the target language.

(b) Students' wants in English knowledge and skills

Concerning their wants, ten interviewed participants openly expressed their opinions on the importance of English knowledge and skills. Their responses are as follows.

First, half claimed that they had a high demand for communication in English, so they found Speaking especially important. They also needed Listening and Pronunciation to complement their communicative abilities.

Usually people verbally communicate with each other, so if listeners don't understand what we are saying, communication fails, and we won't leave any good impressions on them at first sight. (St. C)

Although pronunciation plays a small part in English learning, it is crucial. It makes communication easier. (St. F)

Second, St. B, G, J, and I highlighted the roles of Grammar, Vocabulary, Reading, and Pronunciation as these English components were found in national exam papers.

I think vocabulary and grammar are the most critical components to me at present because they play an integral part in the upcoming national exam. For this reason, I must be good at them to get a high score in the exam. (St. I)

When asked about areas of English knowledge and skills teachers most spent in, all interviewed participants stated that their English teachers spent most of the time giving instructions and practices related to written national exams, namely Grammar, Vocabulary, and Reading. They said,

In English classes, the teacher teaches us Grammar, Vocabulary, and other stuff to choose correct answers in national exams. Therefore, we are rarely offered communicative skills despite being English-majored students at a gifted high school. (St. E) 
Arab World English Journal (AWEJ) Volume 12. Number 3. September 2021

Gifted High School Students' Needs for English Learning in Vietnam

Do \& Nguyen

\section{(c) Students' satisfaction}

Concerning their satisfaction with what they practiced in the classroom, eight out of ten participants showed their dissatisfaction.

As I mentioned, I expected to be offered more Speaking lessons, but learning materials focus too much on Grammar and what serves more for college entrance exams. (St. E)

However, St. C and D said that their wants were met relative to the constraints facing their English teachers in the classroom.

I think that the present English learning courses met my basic needs of Listening, Speaking, and Pronunciation. We cannot blame the teacher for not providing enough what we need because how she can meet her thirty-five students' needs within 45 or 90 minutes, so the problem is that we cannot get a lot of chances to speak English in such a big class. (St. C)

After having experienced the curriculum specially designed for English-majored students at gifted high schools, the participants gave suggestions for improvements. First, St. A, B, C, F, G, and $\mathrm{H}$ stated that there should be an increase in Speaking and Listening in English classes, and learning materials of these two skills should be authentic and significantly related to real-life situations. Second, more English eloquence contests and online competitions should be organized to stimulate the spirit of English learning among students. Third, St. F, G, I, and J suggested that English classes should be a place where every student feels free and self-confident to express their ideas and communicate with teachers as well as classmates. For St. J and F, teachers need to update their teaching methodologies, add more presentations, and increase teacher-student and student-student interaction in English.

\section{Discussion}

This section discusses the findings with regard to the two research questions addressed above: (1) How do gifted high school students describe their needs for English learning? (2) How much do they feel satisfied with the English practices provided?

First, in terms of necessities for learning English, statistical findings revealed that learning English to get a good job in the future was most agreed by the participants. Additionally, when the interviewees were asked to give their opinions on that prioritized purpose, they all agreed that English was a helpful tool to find a good job in the future. Added to that prime target situation, in both questionnaire and interview results, they mostly opted for other anticipated necessities such as academic fulfillments/achievements, cross-cultural/national communications, traveling abroad, and personal interests. These findings are found to be substantially consistent with those reported in many previous studies postulating that employment opportunity necessitates the need to learn English as a foreign language among nonEnglish speaking countries, followed by other secondary purposes such as abroad-traveling and further educations (Akbari, 2016; Gass, 2012; Lou et al., 2020; Nurakhia \& Palupi, 2018; Priya, 2014). In other words, despite different socio-cultural backgrounds, individual characteristics, and country-economic-level development, most EFL learners worldwide need to learn English for the primary employment-related purpose and other additional ones, including exam-passing as an urgent/short-term need, and across-border communications and travels as long-term ones. This trend can be accounted for by the widely accepted fact that English (also well-known as a lingua franca) has so far played a critical means of global communication in virtually all fields and aspects of life, especially e-commerce, banking, and education. Furthermore, there is no 
denying the fact that this globally common language should turn out to be a prerequisite for the entire world (regardless of political disputes and cultural differences) cooperatively combatting life-threatening impacts of currently significant challenges like climate change and the widespread pandemic Covid-19. Although participants in the current study were still high schoolers (entering their adulthood), virtually all of them confidently understood why they needed to be learning English. Interestingly, parental intervention or imposition did not seem to play a vital role in this scenario to the student sample (see item nine, Table four). This particular finding has yet to be addressed in previous research, especially among the ones from Vietnam context (such as Ho, 2017; Loan \& Dan, 2018; Nguyen, 2011; Nguyen 2021), where parents traditionally tend to play a part in their children's orientation of education and future careers.

Secondly, about their wants, Speaking and Listening were deemed the most essential components of English learning, while Grammar was the least important, so most students explicitly wanted to be offered more Speaking-Listening practices, but less Grammar than the other components (Reading, Writing, Vocabulary, and Pronunciation). The interview results confirmed this finding because some argued that they could practice Grammar-Vocabulary at home without their classmates' or teachers' assistance, but they could not do that with SpeakingListening. In other words, they needed partners/classmates to practice English communicative skills (orally) with and teachers to correct their mistakes (if any) in Speaking. Thus, they are highly aware of the paramount importance of Speaking in verbal communication because poor English speaking is likely to deliver wrong impressions on other people during first encounters and because English-speaking/practicing environments are solely found explicitly in the classroom of Vietnam's present context. This finding echoes some previous research reports such as Chao (2016), Ho (2017), and Lou et al. (2020), in which participants needed more practice in English speaking. However, only the current study provides clear accounts for students' need of someone else, both practicing English speaking (classmates/teachers) and helping correct their mistakes (preferably their teachers). On the other hand, some interviewees also admitted that although they had high-level needs of Speaking-Listening for communication, they would practice more Reading, Grammar, and Vocabulary instead because upcoming national exams had neither Speaking nor Listening requirements (no test papers on these two skills).

Thirdly, the mismatch between learners' wants and in-class English practices (provided by in-charge teachers) is another consistency in pertinent findings over some past studies to the current one (Akbari, 2016; Gass, 2012; Gborsong et al., 2015; Ho, 2017; Loan \& Dan, 2018; Nguyen, 2011). Put it differently, students found their wants met at a very narrow extent over the learning curriculum/courses offered. Thus, it is true that learners are far active, cognitive and independent participants in the acquisition process than is assumed by teachers that what they teach is what learners learn (Long, 2005). Yet, only the current study provides specific evidence of the mismatch backed up by comparatively statistical results with five significant cases (Speaking, Listening, Writing, Grammar, and Pronunciation) and two insignificant ones (Vocabulary and Reading). In addition, the current study also provides interview reports of the students' dissatisfactions openly expressed and their suggestions for improvements (because teachers gave more than enough practices in exam-preparations at the expense of SpeakingListening development). These suggestive voices are worth attending since they can be considered as pedagogical implications for both English teachers and course designers. Noticeably, Speaking-Listening should be consistently at the top of teachers' protocols of lessons authentically adjusted and updated, and classroom environments should become safe 
scaffoldings for students' interactive and communicative endeavors. Also, extra-curricular activities should include English-spoken presentations and inspirational contests/competitions among students.

\section{Conclusion}

The current study attempted to determine students' learning needs and satisfaction in English knowledge and skills via a questionnaire interview design. It involved a sample of 180 participants (who were deemed to excel in English compared to their peers at regular high schools) from five gifted high schools in five provinces of the Mekong Delta, South-West of Vietnam. The obtained results are as follows. First, students opted for learning English because they believed they needed it in prospective employments and cross-cultural/national communications as well as exam preparations and academic achievements. Still, they wanted to practice more English communicative skills. Second, students did not find their wants met satisfactorily because English practices provided in the classroom focused on exam preparations (of Reading, Grammar, and Vocabulary) rather than developing communicative competencies (of Speaking-Listening).

The findings from the current study should be modestly generalized due to a limited number of student participants and schools involved, especially only ten students partaking in the interview. As a result, further research should contain a larger population sample from more gifted high schools for both questionnaires and interviews. Classroom observation should be added to triangulate collected data. On the other dimension, future studies should invest in English teachers' attention to students' learning needs and follow-up activities (if any, such as course plans, teaching methods, materials, and lessons adjusted and updated to satisfy students' needs better). The recent study of Chatzikyriakou and Zafiri (2019), as discussed above, is an example from the teachers' dimension in this scenario.

\section{About the authors}

Dr. Do Minh Hung has been teaching English at Dong Thap University, Cao Lanh City, Dong Thap Province, Vietnam, for more than 20 years. He holds a doctoral degree in Applied Linguistics and has published several journal articles in the areas of English instruction and English-Vietnamese translation. ORCID ID https://orcid.org/0000-0001-9140-8404

Ms. Nguyen Thi Thu Ai is an English teacher at Ca Van Thinh High School, Ben Tre City, Vietnam. She has worked there for more than 12 years. She received his MA degree in TESOL from Can Tho University, Vietnam.

\section{References}

Akbari, Z. (2016). The study of EFL students' perceptions of their problems, needs, and concerns over learning English: The case of MA paramedical students. Procedia - Social and Behavioral Sciences, 232, 24 - 34. DOI: 10.1016/j.sbspro.2016.10.006

Al Hilali, T.S., \& Mckinley, J. (2021). Exploring the socio-contextual nature of workplace writing: Towards preparing learners for the complexities of English L2 writing in the workplace. English for Specific Purposes, 63(July 2021), 86-97. DOI: 10.1016/j.esp.2021.03.003 
Bhattacherjee, A. (2012). Social science research: principles, methods, and practices. South Florida: Scholar Commons.

Brindley, G. (1989). The role of needs analysis in adult ESL programme design. In R. K. Johnson (Ed.), The second language curriculum (pp. 63-78). Cambridge: Cambridge University Press. DOI: 10.1017/CBO9781139524520.007

Brown, J. D. (1995). The elements of language curriculum: A systematic approach to program development. Boston, MA: Heinle \& Heinle.

Cao, T. H. P., Ta, T. B., \& Hoang, B. C. (2016). National policies for teaching English contexts: a discussion of policies. Thai TESOL Journal, 29(2), 1-17.

Chatzikyriakou, M., \& Zafiri, M. (2019). Needs analysis in EFL teaching in Greece, the teachers' stance. Education and Linguistics Research, 5(1), 1-20. DOI: 10.5296/elr.v5i1.14191

Creswell, J. W. (2014). Research design: Qualitative, quantitative, and mixed methods approaches ( $4^{\text {th }}$ Ed.). Thousand Oaks, California: Sage.

Dissanayake, K. M., \& Harun, R. N. S. R. (2012). Theory and practice of EAP in the Sri Lankan context. Procedia - Social and Behavioral Sciences, 66, 106 - 116.

Dooey, P. (2010). Students' perspectives of an EAP pathway program. Journal of English for Academic Purposes, 9(3), 184-197.

Gass, J. (2012). Needs analysis and situational analysis: Designing an ESP curriculum for Thai nurses. English for Specific Purposes World, 36(12), 1-21.

Gborsong, P. A. et al. (2015). A needs analysis of undergraduate students of communicative skills: the case of tertiary institutions in Ghana. Open Journal of Modern Linguistics, 5, 413-424. DOI: 10.4236/ojml.2015.55037

Ho, N. Q. (2017). English learning needs of Business Administration students: factors to consider in ESP curriculum development. Tạp chí Khoa họ Ngôn ngũu và Văn hóa [Journal of Language Science and Culture], 1(1), 59-71.

Hutchinson, T., \& Waters, A. (1987). English for specific purposes: A learning-center Approach. Cambridge: Cambridge University Press.

Ibrahim, A. S. E. M. (2016). ESP needs analysis: A case study of PEH students, University of Khartoum. Sino-US English Teaching,13(12), 1-19. DOI: 10.17265/1539$\underline{8072 / 2016.12 .00}$

Kazar, S. G., \& Mede, E. (2015). The perceptions of ESP students' target needs: A case study. Procedia - Social and Behavioral Sciences, 191, 2526 - 2530.

Kendall, L. (2008). The conduct of qualitative interview: Research questions, methodological issues, and researching online. In J. Coiro, M. Knobel, C. Lankshear, \& D. Leu (Eds.), Handbook of research on new literacies (pp.133-149). New York: Lawrence Erlbaum Associates.

Loan, D.T., \& Dan, T.C. (2018). An evaluation of general English course from non-English major students' learning needs analysis. Can Tho University Journal of Science, 54(2), 56-66.

Long, M. H. (Ed.) (2005). Second language needs analysis. Cambridge: Cambridge University Press. DOI: $10.1017 / \mathrm{CBO} 9780511667299$

Lou, Y.G., Li, H.X., \& Zhao, Z.J. (2020). A study on needs analysis of Chinese vocational nonEnglish majored undergraduates in English for specific purposes. Open Access Library Journal, 7(5), 1-15. 
MOET. (2014). Quy chế: Tổ chức và hoạt động của trương trung học phổ thông chuyen. [Regulations: Organizations and activities of gifted high schools].

Nguyen, A. T. (2011). Learners' academic and occupation needs in ESP course (English for civil engineering) at a vocational college in the Mekong Delta, (Unpublished Master's thesis). Can Tho University, Vietnam.

Nguyen, T. Q. et al. (2021). A needs analysis of Vietnamese users of Japanese, Korean, and Chinese languages. VNU Journal of Foreign Studies, 37(2), 112-135.

Nunan, D. (1988). The learner-centered curriculum. Cambridge: Cambridge University Press.

Nurakhia, A., \& Palupi, F. N. (2018). Exploring ESP needs of undergraduate nursing students in a university in Indonesia. Advances in Social Sciences Research Journal, 5(7) 77-85.

Poedjiastutie, D., \& Oliver, R. (2017). English learning needs of ESL learners: exploring stakeholders perceptions at an Indonesian university. TEFLIN Journal, 28(1), 1-21. DOI: 10.15639/teflinjournal.v28i1/1-21

Priya, S. (2014). Lacunas identified in syllabus design of English language teaching in Engineering Colleges: A study with special reference to Odisha, India. International Journal of English Language \& Translation Studies, 2(4), 34-51.

Read, J. (2008). Identifying academic language needs through diagnostic assessment. Journal of English for Academic Purposes, 7(3), 180-190. DOI: 10.1016/j.jeap.2008.02.001

Seedhouse, P. (1995). Needs analysis and the general English classroom. ELT Journal, 49, 5965.

Sönmez, H. (2019). An examination of needs analysis research in the language education process. International Journal of Education \& Literacy Studies, 7(1), 8-17.

White, R. V. (1988). The ELT curriculum design, innovation, and management. Oxford: Basil Blackwell.

Zafar, S. A. (2020). What it takes to design the best model for the English for academic purposes course? English for Specific Purposes World, 22(60), 1-27.

Appendix A: Interview protocol

(1) Why did you opt to study English?

(2) How important are English language knowledge and skills to you?

(3) What English components and skills do you want to focus on?

(4) Which English components and skills did your teacher focus on in the classroom?

(5) Did you feel satisfied with the English practices provided?

(6) Do you have any suggestions to better the English learning course at your school? 